Buxton, E. W. (1954). J. gen. Microbiol. 10, 71-84

\title{
Heterocaryosis and Variability in Fusarium oxysporum f. gladioli (Snyder \& Hansen)
}

\author{
BY E. W. BUXTON \\ The Botany School, University of Cambridge
}

\begin{abstract}
SUMMARY: The basis of variation in morphological appearance of first cultures of Fusarium oxysporum $\mathrm{f}$. gladioli, isolated from diseased roots and corms of prematurely yellowed Gladiolus plants, was investigated. The occurrence of mutations is considered to be far too infrequent to account for the wide range of variability of the fungus in culture, and the existence of heterocaryons of mixed morphologically distinct genotypes is considered.

Cytological studies show that each microconidium contains one nucleus which is derived by mitosis from the single nucleus of the conidiophore. Hyphal tip cells contain an average of seven nuclei whilst the cells behind, in the older parts of the hyphae, contain only one nucleus each or, more rarely, two. Anastomoses between germ tubes from conidia of different morphological variants occur very frequently and may provide a means whereby heterocaryons are formed.
\end{abstract}

Synthesis of heterocaryotic cultures is achieved by simultaneous inoculation of plates containing plain water agar medium. Hyphal tips were separately removed from the mixed colonies thus produced and analysed by single-sporing the resulting colonies. Media varying in carbon content and in carbon/nitrogen ratio proved to have a selective action upon one or other of the homotypes constituting a heterokaryon of two known morphologically distinct variants. By use of such media, it was shown that the ratios of nuclei homotypic for 'flat sporodochial' and 'aerial microconidial' variants was altered according to the relative concentrations of carbon or nitrogen in the culture medium.

A discussion follows on the bearing of these results on the reliability of hitherto important taxonomic criteria in a classification of these fungi. The isolates of $F$. oxysporum $\mathrm{f}$. gladioli include a wide range of morphological variants which may be included in Snyder \& Hansen's $F$. oxysporum. The existence of heterocaryons between taxonomic variants and their plasticity under various cultural conditions, poses the question of their status in any satisfactory classificatory system.

The frequent occurrence of variants in culture of species of Fusarium has long been the cause of serious difficulty in the definition of the taxonomic features of the genus. A realization of this variability led Appel \& Wollenweber (1910) to define the cultural states of Ankultur, Normkultur and Hochkultur so that the taxonomic criteria were related to certain stages of the organisms in culture. Snyder \& Hansen (1945) suggested that the considerable overlapping of morphological characteristics, hitherto considered to be sufficiently stable for taxonomic purposes, necessitates a complete revision of the genus. Brown (1925, 1926, 1928) and Brown \& Horne (1924, 1926) demonstrated the marked effect on fusaria of cultural management and selection. Snyder \& Hansen reduced the sixty-five species of Wollenweber \& Reinking's classification (1935) to eight. Miller (1946), working with culture variants of Fusarium isolated from wilted muskmelon plants, concluded that the forms in which Fusarium occurs in nature possess few or none of the established features used 
by Wollenweber as taxonomic criteria. This undifferentiated stage, the 'wildtype' according to Miller, is characterized by 'abundant aerial mycelium on which conidia, mostly non-septate, are borne rather sparsely'. The traditional sporodochia, macroconidia, sclerotia and pionnotes are held to occur in culture only, as a result of mutation. The validity of such taxonomic criteria Miller, therefore, holds open to doubt. This point of view was challenged by Subramanian (1951) who, working with Fusarium isolates of the Martiella, Elegans, Gibbosum and Arthrosporiella sections from various diseased host-plants, concluded that 'species of Fusarium occur in nature in a multiplicity of forms and not as a single wild-type as claimed by Miller. Since sporodochia were produced by a large number of isolates immediately after isolation in first cultures, these are a natural characteristic of the genus and should be of value in taxonomic studies.' None of these authors has considered in detail the basis of the variation reported, but it is fair to say that, following the work of Hansen (1938) on Botrytis, Beadle \& Coonradt (1944) on Neurospora and Pontecorvo (1946) on Penicillium and other Fungi Imperfecti, it has been tacitly assumed that much of the variability is due to the heterocaryotic association of unlike nuclei in the same mycelium. The relative importance of mutation in initiating the heterocaryotic condition is not considered, apart from Miller's work.

In a study of a disease of Gladiolus caused by Fusarium oxysporum $\mathrm{f}$. gladioli (Buxton \& Robertson, 1953) considerable variation was met with in the first isolates from diseased corms with respect to colour, colony type and the taxonomically important criterion of macrospore production. At one extreme isolates produced abundant macroconidia on sporodochia and as pionnotes and could be referred to $F$. oxysporum var. gladioli as described by Massey (1926), whilst at the other they possessed few, straight, macroconidia in the aerial hyphae and could be referred to $\boldsymbol{F}$. orthoceras var. gladioli as described by McCulloch (1944). The basis of this type of variation, which is of common occurrence in Fusarium (Snyder \& Hansen, 1940), and which is responsible for much of the difficulty in Fusarium taxonomy has been little investigated. This material seemed favourable for making inquiries along the following lines: $(a)$ how far the variation might be due to mutation alone; $(b)$ how far it might be due to the segregation of the natural isolates into their component homotypes; $(c)$ how stable the heterocaryons were, if formed, and how far they were influenced by the nutritive status of the culture medium; $(d)$ what was the phenotypic expression of distinct taxonomic characters in such heterocaryons. An account of these investigations is given below.

\section{MATERIAL}

The first isolates of Fusarium from diseased corms of yellowed Gladiolus plants were grown on $2 \%$ potato-glucose agar at $25^{\circ}$. Several sectors varying in colour, production of macroconidia as flat pionnotal areas and relative abundance of aerial mycelium were noted and subcultured, being purified later by single spore isolations. Sample isolates of this type are listed in Table 1 below. During the course of subsequent experiments, several hundred 
subcultures of single spore origin were made of each of these variants and in one case only was there any recognizable occurrence of a mutant from the progeny of these single spore parent colonies. Five pale-violet coloured colonies (not dealt with in this work) occurred as mutants from a set of c. 1000 single spores of the purple-vinaceous culture no. 90. The separate variants, therefore, appear to be sufficiently stable for use in the subsequent investigations in which the genetic markers are required to be reasonably distinct and reliable.

\section{INVESTIGATION OF THE HETEROCARYOTIC NATURE OF THE FUNGUS}

\section{Distribution of the nuclei in the mycelium and spores}

As a preliminary to the experimental synthesis and subsequent analysis of Fusarium heterocaryons it was considered necessary to investigate the distribution of nuclei in the hyphae, conidiophores and conidia of the fungus. Colonies were obtained on glass cover-slips from small drops of plain water agar seeded with mixed-spore suspensions from cultures of red and white variants of the Fusarium. At various stages of growth the colonies were fixed in Carnoy's fluid for $25 \mathrm{~min}$., hydrolysed in $\mathrm{N}-\mathrm{HCl}$ for $10 \mathrm{~min}$. at $60^{\circ}$ and subsequently stained for $30 \mathrm{~min}$. in a mixture of aqueous $2 \%$ Azure ' $\mathrm{A}$ ', $\mathrm{NaHSO}_{4}$ and $\mathrm{N}-\mathrm{HCl}$ (see Heubschman, 1952). The staining of conidia was facilitated by sticking them to cover-slips with egg albumin. Since an estimate of the distribution and proportions of each nuclear type in the heterocaryon was required, an examination was made of stained preparations showing different stages in conidial formation and its accompanying nuclear behaviour. It was found that the single nucleus of each microconidium was formed by division of the nucleus of the conidiophore. This indicates that each conidiophore is capable of abstricting only one genetic type of conidium. In a heterocaryon this would probably mean that the relative numbers of the two genetic types of conidia produced would bear some relationship to the initial ratio of the two types of nucleus in the original mycelium. Any variations in the ratio of the two types of conidia produced would accrue from a differential rate of nuclear division in the conidiophores containing either of the two types of nucleus. Stages in conidial formation are shown in Fig. 1.

The cells of the mycelium were found to contain, in almost every case, one nucleus only, except in the cases of cell division, these being adjacent to the growing tips of the hyphae, or to cells involved in conidiophore or conidium formation. The hyphal tips possessed no septa for some distance from their growing ends and terminal cells contained a number of nuclei varying, in an even distribution, from 1 to 15 . In a sample of fifty-three hyphal tips examined, the mean number of nuclei in the terminal cells was seven. Therefore, on cytological grounds alone it would appear to be impossible for the mycelium to exist as a collection of heterocaryotic cells as it does, for example, in Botrytis (Hansen, 1938), since each portion of the hyphae cut off between septa contains only one nucleus. That is, on the strict 
definition 'heterocaryon', no such state can exist in the mature mycelium of $F$. oxysporum unless it can be shown that the inter-connexions between the
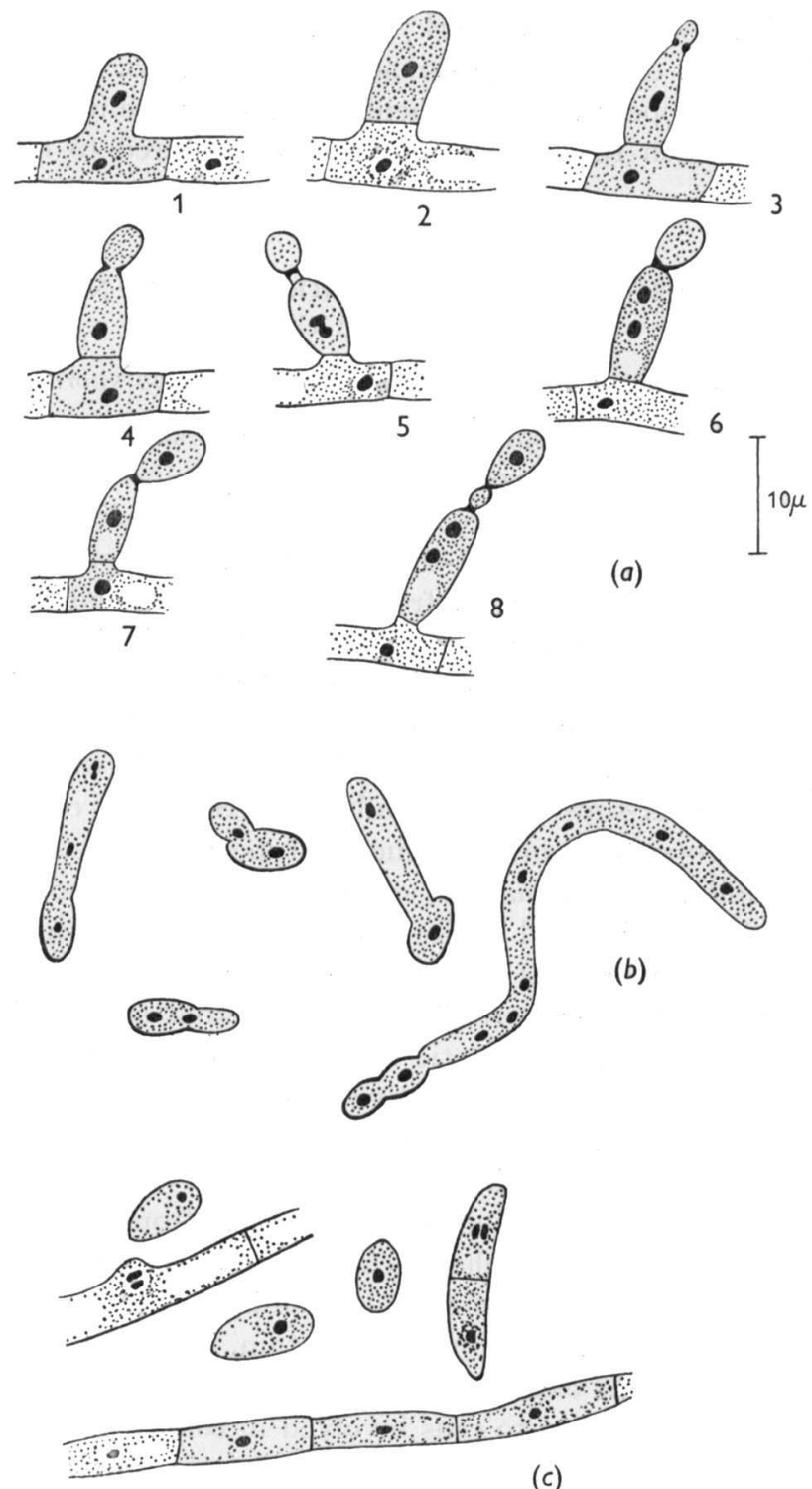

(c)

Fig. 1. (a) Stages in microconidial differentiation showing the distribution of the nuclei involved-stained by Azure ' $A$ ' method (see text). (b) Germinating conidia showing a number of nuclei in the germ tubes which are not yet divided by septa. (c) Hyphae and conidia showing single nucleus per cell. Nuclei in a final stage of division appear in two of the cells.

'cells' of hyphae are of such magnitude that the mycelium is for practical purposes coenocytic. Whether or not the mycelium acts as a functional heterocaryon 
is considered later. What is clear is that the microconidia and the macroconidia must obtain nuclei which are effectively segregated in one cell and therefore it is at least theoretically impossible for them to contain nuclei of more than one type, unless mutation has occurred.

Evidence of anastomosis. Stained preparations of germinating conidia showed that a considerable number of anastomoses occurred soon after the germ tubes were produced. Such anastomoses appeared to be more frequent when conidia were germinated in water on a glass surface. The two cultures used had been separately isolated from the roots and vascular core of corms of yellowed Gladiolus taken from the field; one culture exhibited a persistent whitish buff colour, the other a deep purple-vinaceous ground colour which diffused into the agar medium. Mixed spore suspensions from these two different morphological types of $F$. oxysporum f. gladioli (i.e. isolates $81 \mathrm{~A}$ and 90-see Table 2) were sown and anastomoses between the germ tubes were observed (see Pl. 1, fig. 2). Almost all these microconidia, which were indistinguishable morphologically, formed anastomoses; hence it could be assumed that the two variant types of germ tube were involved in anastomoses with each other. Macroconidia from variant $81 \mathrm{~A}$ produced germ tubes which freely anastomosed with those produced by microconidia of variant 90 . The use of macroconidia and microconidia respectively in this latter case determined the exact origin of each of the component hyphae of the observed anastomoses. A considerable number of anastomoses between older hyphae of mixed inoculum were frequently observed in cultures grown on water agar (see Pl. 1, fig. 3). Conidia stained (Azure 'A' method) to show the nuclei are shown in Pl. 1, fig. 1.

Evidence of heterocaryosis. In the course of work already carried out on the Fusarium Yellows disease of Gladiolus (Buxton \& Robertson, 1953) by far the most frequent variants found in the original isolates were those concerning colour of mycelium and presence or absence of high abundant aerial mycelium. Sample variants of these types are shown in Table 1. All cultures

\section{Table 1. Typical variants occurring as sectors from isolates of Fusarium oxysporum $f$. gladioli}

Cultural features are all as shown on potato glucose agar medium. Different patterns were, however, obtained on several other media.

\begin{tabular}{|c|c|c|c|c|}
\hline $\begin{array}{l}\text { Isolate } \\
\text { no. }\end{array}$ & $\begin{array}{l}\text { Colour on } \\
\text { potato glucose } \\
\text { agar medium }\end{array}$ & Mycelial type & Sporodochia & $\begin{array}{l}\text { Pionnotes } \\
\text { (slime-spore } \\
\text { masses) }\end{array}$ \\
\hline 90 & Red & $\begin{array}{l}\text { Sparse, slightly } \\
\text { raised in close mat }\end{array}$ & Absent & Absent \\
\hline $81 \mathrm{~A}$ & White-buff & $\begin{array}{l}\text { Abundant, high, } \\
\text { cottony }\end{array}$ & $\begin{array}{l}\text { Abundant (on } \\
\text { oatmeal agar). } \\
\text { Pale buff colour }\end{array}$ & Absent \\
\hline $81 F$ & White & $\begin{array}{l}\text { Adpressed, twisted } \\
\text { together. No } \\
\text { aerial mycelium }\end{array}$ & Absent & $\begin{array}{l}\text { Abundant in } \\
\text { light }\end{array}$ \\
\hline 13 & Grey-white & $\begin{array}{l}\text { Adpressed, twisted } \\
\text { into thick 'ropes'. } \\
\text { No aerial mycelium }\end{array}$ & Absent & Absent \\
\hline
\end{tabular}


were defined on a standard medium made by adding $20 \mathrm{~g}$. glucose and $20 \mathrm{~g}$. agar to $1 \mathrm{l}$. of potato extract ( $200 \mathrm{~g}$.potato/l.).

Single-spore cultures were obtained of each cultural type, and from these in turn single spores were taken in order to ensure genetic purity. Spore suspensions from two of the single-spore colonies of different types were sown mixed on water agar plates and the resulting colony allowed to grow to $c .2 .5 \mathrm{~cm}$. diam. At this stage, with the use of a finely pointed needle, single hyphal tips of $c .150 \mu$. length were carefully cut away from the advancing edge of the colony and transferred singly to separate tubes of the standard potatoglucose agar medium. These single hyphal tips were grown until a stage of sporulation was reached, i.e. 3-4 days, after which time spore suspensions from each were separately spread over Petri plates containing the standard medium. A suitable dilution produced colonies which could be easily counted and classified into one or other of the two homotypes used for the original synthesis of the heterocaryon. The results of an experiment of this type are shown in Table 2.

Table 2. Analysis of heterocaryons produced by mixed-spore inoculum of two morphological types of Fusarium oxysporum $f$. gladioli

\begin{tabular}{|c|c|c|c|}
\hline \multirow[b]{2}{*}{ Inoculum } & \multirow{2}{*}{$\begin{array}{c}\text { Appearance of colonies from } \\
\text { hyphal tips }\end{array}$} & \multicolumn{2}{|c|}{$\begin{array}{l}\text { Homotypes resulting } \\
\text { from single-sporing the } \\
\text { hyphal-tip colonies }\end{array}$} \\
\hline & & 90 & 13 \\
\hline Mixed 90 and 13 & Greyish purple, slightly aerial & \begin{tabular}{l|}
54 \\
44 \\
48 \\
63 \\
56 \\
47
\end{tabular} & $\begin{array}{l}c .200 \\
\text { c. } 500 \\
\text { c. } 250 \\
\text { c. } 350 \\
\text { c. } 300 \\
\text { c. } 300\end{array}$ \\
\hline Controls 90 and 13 & $\begin{array}{l}\text { Purple-vinaceous, aerial } \\
\text { Grey-white, not aerial }\end{array}$ & $\begin{array}{l}\text { c. } 800 \\
\text { Nil }\end{array}$ & $\begin{array}{l}\text { Nil } \\
\text { c. } 800\end{array}$ \\
\hline
\end{tabular}

A similar experiment using variants $81 \mathrm{~A}$ and $81 \mathrm{~F}$ showed again that hyphal tips from mixed-spore colonies segregated into their original components. The smaller numbers involved are due to the fact that single-spore colonies were picked off immediately on germination with the use of the eye of a sewing needle, thereby ensuring that only one spore colony was removed at a time. The results are given in Table 3.

The production of some homocaryotic hyphal tips indicated, as might be expected, that localized breakdown of the heterocaryon had occurred. In order to investigate this possibility, separate hyphal branches at the leading edge of colonies of mixed-spore origin grown on water agar were cut free and cultured separately on potato glucose agar. Examples of this type are shown in Fig. 2.

The examples depicted in Fig. 2 illustrate the mechanism by which sectoring is likely to occur owing to the branching of a heterocaryon into its separate components, thus leading ultimately, provided that continued growth of the separate component takes place, to the production of sectors. These sectors 
Table 3. Analysis of heterocaryons produced from mixed-spore inoculum of two morphological variants, $81 \mathrm{~F}$ and $81 \mathrm{~A}$, of Fusarium oxysporum $f$. gladioli

Inoculum

Mixed $81 \mathrm{~F}$ and $81 \mathrm{~A}$

Controls 81 F

$81 \mathrm{~A}$

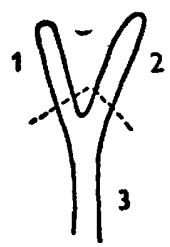

A

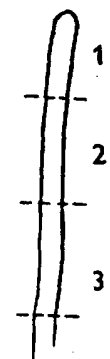

D
Appearance of colonies from hyphal tips

As $81 \mathrm{~A}$

Intermediate, flat with aerial wisps Intermediate, flat with aerial wisps

As $81 \mathrm{~A}$

As $81 \mathrm{~F}$

As $81 \mathrm{~F}$

As $81 \mathrm{~A}$
Homotypes resulting from single-sporing the hyphal-tip colonies

$\begin{array}{rc}81 \mathrm{~F} & 81 \mathrm{~A} \\ 0 & 30 \\ 8 & 22 \\ 12 & 18 \\ 0 & 30 \\ 30 & 0 \\ 30 & 0 \\ 0 & 30\end{array}$
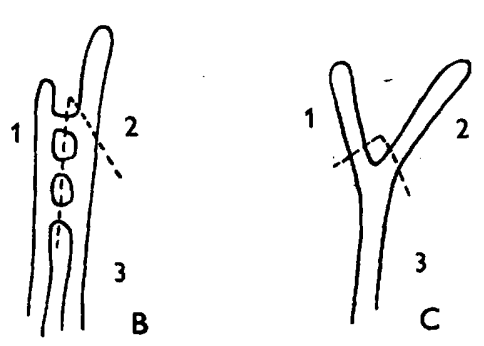

B
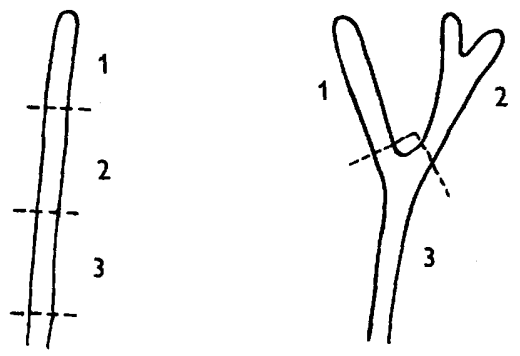

F

Fig. 2. Examples of branching heterocaryotic hyphae and the resulting colonies produced when the separate components were transferred to potato glucose agar medium. A, B, $\mathrm{C}$ and $\mathrm{D}$ are heterocaryons of 90 and $81 \mathrm{~A}$. $\mathrm{E}$ and $\mathrm{F}$ are heterocaryons of $81 \mathrm{~F}$ and $81 \mathrm{~A}$. Incisions were made along the dotted lines. Colonies from the excised fragments were as follows: A1: 90 and $81 \mathrm{~A}$; A2: $81 \mathrm{~A} ; \mathrm{A3}: 90$. B1: 81 A; B2: 90; B3: no growth. C1 : 90; C2: 81 A; C3 : no growth. D1 : $81 \mathrm{~A} ; \mathrm{D2}: 90$ and $81 \mathrm{~A} ; \mathrm{D3}: 90$ and $81 \mathrm{~A}$. E1: $81 \mathrm{~A}$ and 81 F; E2: 81 A; E3: $81 \mathrm{~A}$ and 81 F. F1: $81 \mathrm{~A}$; F2: 81 A; F3: $81 \mathrm{~A}$ and $81 \mathrm{~F}$.

are usually evident as fans of a different morphological appearance; they may be overgrown by the heterocaryon or by the sectors of the other homotype. Thus the heterocaryon may be re-synthesized at any time during the growth of the colony by means of anastomoses between the two homotypes (see Pl. 1, fig. 3). With continued growth, the hyphal tip leaves behind a chain of cells of different nuclear type. It seemed possible, therefore, that one or other of the nuclear types might be differentially selected so that the cells laid down, as the colony expands, will differ in proportionate numbers. 
If we consider a hyphal tip containing two types of nuclei, it is clear that, with subsequent divisions of each of these two types, such a tip will become homocaryotic for the terminal nucleus (see Fig. 3). Thus the older colonies will show a higher proportion of homocaryotic hyphae on their advancing margin, although there are two possibilities which may be considered which could reconstitute the heterocaryon in these hyphal tips. First, as shown in Fig. 3, the nuclei may pass each other during the course of mitosisstaining shows that this is physically possible. Secondly, frequent anastomoses, as already demonstrated between advancing young hyphae at the colony edges, may facilitate transfer of nuclei, thus reconstituting the heterokaryon.

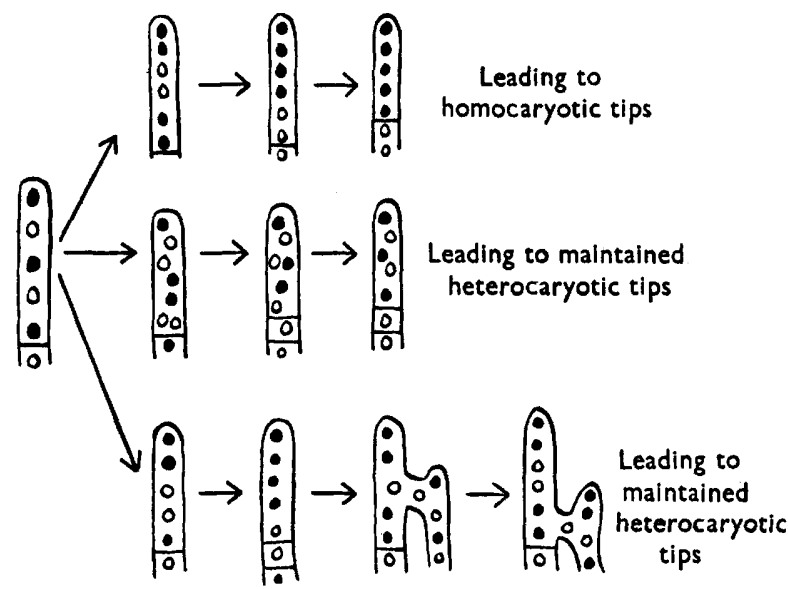

Fig. 8. Possible fate of young hyphal tips, leading to a homocaryotic state or, by two possible methods, to a maintained heterocaryotic state

The re-synthesis of heterocaryotic patches, which may or may not break down at a later stage by branching, as depicted in Fig. 2, leads to the formation of a complex nuclear arrangement which is probably best described as a 'mosaic' of the two variants involved. Since this mosaic is constituted at an early stage by numerous anastomoses between germ tubes of the conidia from the two variants, and since branching into the two homotypes may occur at any subsequent stage, it was deemed necessary to compare the nuclear ratios of pieces of hyphae taken from the centre of mixed culture with those at later stages of growth, i.e. at different points along the radius of a colony. The results of such an experiment are given in Table 4, which further substantiates the conception of the two nuclear types as co-existing as a mosaic colony, since some hyphal fragments return a completely homocaryotic range when single-spored.

A similar experiment with variants $81 \mathrm{~A}$ and 90 gave the same pattern of random juxtaposition of homocaryotic and heterocaryotic hyphae within the mixed-spore colony.

Selection by the culture medium. The possibility of the variation of the nuclear ratio by a change in the nutritive status of the medium was investi- 
Table 4. A comparison of nuclear proportions in hyphal fragments taken from points at different distances from the centre of a mixed-spore colony of variants $81 \mathrm{~F}$ and $81 \mathrm{~A}$

\begin{tabular}{|c|c|c|c|c|c|c|c|}
\hline \multirow[b]{4}{*}{ Inoculum } & \multirow{4}{*}{$\begin{array}{c}\text { Distance } \\
\text { from centre } \\
\text { of colony at } \\
\text { which hyphal } \\
\text { fragment } \\
\text { cut } \\
\text { (cm.) }\end{array}$} & \multirow{4}{*}{$\begin{array}{l}\text { Appearance of } \\
\text { hyphal fragment } \\
\text { colonies }\end{array}$} & \multicolumn{5}{|c|}{$\begin{array}{l}\text { Colony types resulting from single- } \\
\text { sporing the hyphal fragment colonies }\end{array}$} \\
\hline & & & \multirow{2}{*}{\multicolumn{2}{|c|}{ Homocaryotic }} & \multicolumn{3}{|c|}{ Heterocaryotic } \\
\hline & & & & & & & Ratio \\
\hline & & & F & $\mathbf{A}$ & $\mathbf{F}$ & $\mathbf{A}$ & F/A \\
\hline \multirow[t]{7}{*}{$\begin{array}{l}\text { Mixed } 81 \mathrm{~F} \\
\text { and } 81 \mathrm{~A}\end{array}$} & $0 \cdot 2$ & $\begin{array}{l}\text { Intermediate } \\
\text { between flat and } \\
\text { aerial types }\end{array}$ & 一 & - & 1037 & 301 & $3 \cdot 4$ \\
\hline & $0 \cdot 4$ & $\begin{array}{l}\text { Intermediate } \\
\text { between flat and } \\
\text { aerial types }\end{array}$ & $\longrightarrow$ & - & 849 & 63 & $13 \cdot 5$ \\
\hline & 0.4 & Flat type & 450 & 0 & - & - & - \\
\hline & $0 \cdot 6$ & Flat type & 900 & $\mathbf{0}$ & - & - & - \\
\hline & $0 \cdot 8$ & $\begin{array}{l}\text { Aerial type } \\
\text { Flat type }\end{array}$ & $\begin{array}{r}0 \\
200\end{array}$ & $\begin{array}{r}400 \\
0\end{array}$ & - & - & 一 \\
\hline & $1 \cdot 0$ & $\begin{array}{l}\text { Aerial type } \\
\text { Aerial type }\end{array}$ & $\begin{array}{l}\mathbf{0} \\
\mathbf{0}\end{array}$ & $\begin{array}{l}400 \\
400\end{array}$ & - & - & - \\
\hline & $1 \cdot 2$ & $\begin{array}{l}\text { Intermediate, but } \\
\text { tending towards } \\
\text { aerial type }\end{array}$ & 一 & - & 186 & 250 & $0 \cdot 88$ \\
\hline
\end{tabular}

gated by varying the initial ratio in the mixed-spore inoculum using one type of medium only, and by inoculating a range of media of varying carbon contents using one particular mixed-spore ratio. Variants $81 \mathrm{~F}$ and $81 \mathrm{~A}$ were used in both experiments. In the first experiment, the ratio of the two types of spores was varied between $3: 1$ and $1: 3$, the total numbers in each inoculum droplet being $c$. 150 in each case. The medium used was prepared from an extract of Gladiolus corms with the addition of $20 \mathrm{~g}$. agar/l. The resulting colonies, which were grown in quadruplicate, were single-spored after 4 and 8 days of growth. This was done by removing the whole colonies and thoroughly shaking them separately in tubes of sterile water, thus ensuring a thorough mixing of the two spore types. Suitably diluted spore suspensions from each tube were plated in quadruplicate at a concentration of $c .300$ spores/ plate of medium constituted as follows (g./l. water): glucose, 2.4; peptone, 19; $\mathrm{MgSO}_{4} .7 \mathrm{H}_{2} \mathrm{O}, 0.5 ; \mathrm{K}_{2} \mathrm{HPO}_{4}, \mathbf{1} \cdot 0 ; \mathrm{FeCl}_{3}$, trace; agar, 20. This medium was used since it gave maximum differentiation between the two phenotypes flat $(81 \mathrm{~F})$ and aerial $(81 \mathrm{~A})$. The ratios of spore types recovered in this experiment are shown in Table 5 .

From this experiment it appears that the Gladiolus corm extract agar medium had no selective effect upon the two nuclear types at least up to 4 days after inoculation. After 8 days, however, visible sectors of $81 \mathrm{~A}$ had just appeared and a high return of spores of this type was encountered. In the second experiment of this kind, a mixed-spore inoculum of variants $81 \mathrm{~F}$ and $81 \mathrm{~A}$ of approximately $1: 1$ ratio was used. The media used varied proportionately in their carbon contents (glucose source) as follows: $\mathrm{Co} / \mathrm{N2}, \mathbf{0} \mathrm{g}$. 
glucose; $\mathrm{C} 1 / \mathrm{N2}, 2 \cdot 4 \mathrm{~g}$. glucose; $\mathrm{C} 2 / \mathrm{N} 2,4 \cdot 8 \mathrm{~g}$. glucose; $\mathrm{C} 3 / \mathrm{N} 2,7 \cdot 2 \mathrm{~g}$. glucose; in other respects they were as in the formula on p. 79. From the mixed-spore colonies single spores were isolated as before, after 4 days growth, and spread over plates of the $\mathrm{Cl} / \mathrm{N2}$ medium. The results are shown in Table 6.

Table 5. Recovered ratios of variants $81 F$ and $81 A$ from mixed-spore inoculum on Gladiolus corm extract agar medium

\begin{tabular}{|c|c|c|c|c|c|c|c|}
\hline \multirow{3}{*}{\multicolumn{2}{|c|}{$\begin{array}{l}\text { Ratios in mixed- } \\
\text { spore inoculum. } \\
\text { (Haemocytometer } \\
\text { counts) }\end{array}$}} & \multicolumn{6}{|c|}{ 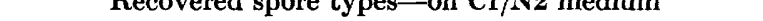 } \\
\hline & & \multicolumn{3}{|c|}{ After 4 days } & \multicolumn{3}{|c|}{ After 8 days } \\
\hline & & \multicolumn{2}{|c|}{ Total colonies } & \multirow{2}{*}{$\underset{\text { F/A }}{\text { Ratio }}$} & \multicolumn{2}{|c|}{ Total colonies } & \multirow{2}{*}{$\begin{array}{c}\text { Ratio } \\
\text { F/A }\end{array}$} \\
\hline $\mathbf{F}$ & $\mathbf{A}$ & F & $\mathbf{A}$ & & $\mathbf{F}$ & $\mathbf{A}$ & \\
\hline 3 & 1 & 943 & 304 & $3 \cdot 10$ & 636 & 230 & $2 \cdot 76$ \\
\hline 2 & 1 & 720 & 402 & 1.79 & 1322 & 325 & 4.06 \\
\hline 1 & 1 & 575 & 550 & 1.00 & 747 & 345 & $2 \cdot 10$ \\
\hline 1 & 2 & 849 & 1369 & 0.62 & 1124 & 497 & $2 \cdot 26$ \\
\hline 1 & 3 & $\mathbf{3 7 4}$ & 1215 & $0 \cdot 31$ & 1041 & 532 & $2 \cdot 00$ \\
\hline
\end{tabular}

Table 6. Recovered ratios from $1: 1$ mixed-spore inoculum of variants $81 F$ and $81 A$ on a range of four media varying in carbon content

\begin{tabular}{|c|c|c|c|c|}
\hline \multirow[b]{3}{*}{ Medium } & \multirow[b]{3}{*}{$\begin{array}{l}\text { Appearance of mixed-spore } \\
\text { colony, after } 4 \text { days' growth }\end{array}$} & \multicolumn{3}{|c|}{$\begin{array}{l}\text { Resulting single-spore colonies after } \\
\text { transfer to } \mathrm{C} 1 / \mathrm{N} 2 \text { medium }\end{array}$} \\
\hline & & \multicolumn{2}{|c|}{ Total colonies } & \multirow[b]{2}{*}{$\begin{array}{c}\text { Ratio } \\
\text { F/A }\end{array}$} \\
\hline & & F & $\overline{\mathbf{A}}$ & \\
\hline $\mathrm{Co} / \mathrm{N2}$ & $\begin{array}{l}\text { White with sparse, high } \\
\text { cottony aerial mycelium }\end{array}$ & 385 & 230 & 1.67 \\
\hline $\mathrm{Cl} / \mathrm{N2}$ & $\begin{array}{l}\text { Whitish buff with woolly } \\
\text { aerial mycelium at centre }\end{array}$ & 475 & 594 & $0 \cdot 80$ \\
\hline C2/N2 & $\begin{array}{l}\text { Whitish buff with woolly aerial } \\
\text { mycelium at centre but lower }\end{array}$ & 119 & 512 & $0 \cdot 23$ \\
\hline $\mathrm{C} 3 / \mathrm{N2}$ & $\begin{array}{l}\text { As C2/N2, but aerial mycelium } \\
\text { only faintly visible }\end{array}$ & 76 & 590 & 0.13 \\
\hline
\end{tabular}

Control plates inoculated with single-spore colonies of the original variants returned 1164 all $81 \mathrm{~F}$ type and 969 all $81 \mathrm{~A}$ type, respectively. Hyphal tips taken from the edges of the initial mixed-spore colonies used in the above two experiments showed, after single-spore isolation by the usual technique, that some heterocaryosis had occurred, although a number of homocaryotic tips were also encountered. It is not, therefore, technically possible to exclude the possibility of homocaryotic hyphae (which may occur de novo or by breakdown of a heterocaryon) growing side by side with heterocaryotic hyphae. The composition of the mosaic does, however, appear to vary in response to the nutritive environment, probably by the selection of one nuclear type at the expense of the other, as in the case of the experiment in which a high glucose content favoured production of spores of the $81 \mathrm{~A}$ type.

A further experiment investigating the evidence for the differential selection of the two homotypes by glucose content was carried out. Hyphal tips from 
heterocaryons of $81 \mathrm{~F}$ and $81 \mathrm{~A}$ type synthesized on water agar were transferred separately to each of the four media of different glucose content and allowed to grow until colonies of $c .1 .5 \mathrm{~cm}$. were produced. Ten hyphal-tip colonies were raised on each of the four media. Each colony was single-spored by spreading over plates of the $\mathrm{Cl} / \mathrm{N2}$ medium as previously described. Subsequent spore counts revealed the results shown in Table 7.

Table 7. Recovered ratios from 1:1 mixed-spore inoculum of $81 F$ and $81 A$ types grown on plain agar medium, later transferred as hyphal tips to a range of four carbon media

\begin{tabular}{|c|c|c|c|c|}
\hline \multirow{3}{*}{$\begin{array}{l}\text { Medium to } \\
\text { which hyphal } \\
\text { tips were } \\
\text { transferred }\end{array}$} & \multirow[b]{3}{*}{ Appearance of heterocaryons } & \multicolumn{3}{|c|}{$\sqrt{2}$} \\
\hline & & \multicolumn{2}{|c|}{ Total colonies } & \multirow[b]{2}{*}{$\begin{array}{c}\text { Ratio } \\
\text { F/A }\end{array}$} \\
\hline & & $\mathbf{F}$ & $\mathbf{A}$ & \\
\hline $\mathrm{Co} / \mathrm{N2}$ & $\begin{array}{l}\text { Fairly flat, white. Sparse } \\
\text { cottony aerial mycelium }\end{array}$ & $\mathbf{3 4 3}$ & 479 & 0.71 \\
\hline $\mathrm{C1} / \mathrm{N2}$ & $\begin{array}{l}\text { As } \mathrm{Co} / \mathrm{N2} \text {, but slightly more } \\
\text { aerial mycelium }\end{array}$ & 158 & 499 & $0 \cdot 33$ \\
\hline $\mathrm{C} 2 / \mathrm{N2}$ & As $\mathrm{C} 1 / \mathrm{N2}$ & 21 & 182 & $0 \cdot 11$ \\
\hline $\mathrm{C3} / \mathrm{N2}$ & As C2/N2, but pale buff & 132 & 464 & $\mathbf{0 . 2 8}$ \\
\hline
\end{tabular}

The heterocaryons showed similar appearances on all four media, being somewhat intermediate between the two component homotypes. It is evident that a heterocaryon which exhibits such a stable morphological appearance on a range of media would, on single-sporing or breakdown by sectoring, yield varying proportions of colonies showing different morphological characteristics.

A further experiment designed to show the effects of two media differing in their glucose/nitrogen ratio upon the relative proportions of the two homotypes in a synthesized heterocaryon was carried out. With $0.2 \%$ carbon (glucose source), $0.1 \%$ nitrogen (peptone source) and 2\% carbon, $0.01 \%$ nitrogen containing media, the same technique was used as in the previous experiment. The results are given in Table 8.

Table 8. Recovered ratios from $1: 1$ mixed-spore inoculum of $81 \mathrm{~F}$ and $81 \mathrm{~A}$ variants grown on plain agar medium, the hyphal tips later transferred to media differing in carbon/nitrogen ratio

An analysis of variance showed an ' $F$ ' value of $16 \cdot 74$, giving significance at $0 \cdot 1 \%$ level. A ' $t$ ' test showed that $t_{[19]}=3 \cdot 96$, giving significance at $0.1 \%$ level.

Medium to which hyphal tips transferred

Low $\mathbf{C} / \mathbf{N}$ ratio

$\underset{\text { ratio }}{\text { High } \mathbf{C} / \mathbf{N}}$

Resulting single-spore colonies from the hyphal-tip colonies

\begin{tabular}{|c|c|c|c|c|c|c|c|c|c|c|c|c|}
\hline $\mathbf{F}$ & 21 & 11 & 16 & 88 & 91 & 85 & 193 & 137 & 174 & 180 & 149 & 191 \\
\hline $\mathbf{A}$ & 10 & 3 & 5 & 87 & 102 & 84 & 125 & 88 & 123 & 143 & 109 & 1 \\
\hline atio $\mathbf{F} / \mathbf{A}$ & $2 \cdot 10$ & $3 \cdot 67$ & $3 \cdot 40$ & 1.01 & $0 \cdot 89$ & 1.01 & 1.54 & 1.56 & $1 \cdot 42$ & 1.26 & $1 \cdot 37$ & $1 \cdot 8$ \\
\hline $\mathbf{F}$ & 43 & 72 & 73 & 74 & 31 & 71 & 47 & 55 & 53 & - & - & $\longrightarrow$ \\
\hline A & 117 & 143 & 104 & 181 & 87 & 134 & 106 & 96 & 86 & - & - & - \\
\hline atio $\mathbf{F} / \mathbf{A}$ & 0.37 & 0.50 & $0 \cdot 70$ & $0 \cdot 4.1$ & $0 \cdot 36$ & 0.53 & 0.44 & $0.5 \pi$ & $0 \cdot 62$ & - & 一 & - \\
\hline
\end{tabular}


The results of these experiments indicate that some advantage is conferred upon the $81 \mathrm{~A}$ component of the heterocaryon used by increasing the glucose content or the glucose/nitrogen ratio of the medium. A count of nuclear ratios, as judged by the proportionate numbers of colonies produced by the single-spore method, gives a clear relationship between the increase of $81 \mathrm{~A}$ and increasing glucose content. In these experiments $81 \mathrm{~F}$ produced masses of macroconidia as pink pseudo-pionnotes and possessed no aerial mycelium, whilst $81 \mathrm{~A}$ formed a woolly colony of buff ground colour and remained nonpionnotal. The production of macroconidia as pionnotes and the colour and texture of aerial mycelium are important criteria in Fusarium taxonomy.

\section{DISCUSSION}

Heterocaryosis may be considered as a basis for the explanation of much of the variability in $F$. oxysporum cultures obtained from so-called 'wild-type' isolates. The initial isolates may exist in the host-plant tissue or in the soil as mycelia of different nuclear types which, when segregated under cultural conditions, yield several colonies showing wide differences in morphological characteristics. It is clear that the media employed in the culture of such natural isolates provide a selective environment for the phenotypic expression of the different potentialities of the wild-types. In the section Elegans of the fusaria, some of these variants have been given taxonomic status by Wollenweber \& Reinking (1935). The evidence presented here supports the decision of Snyder \& Hansen (1940) in placing the old species of this section into the single macro-species $\boldsymbol{F}$. oxysporum, having several formae accommodating the different pathogenic isolates. Heterocaryons between taxonomic types of the isolates from diseased gladioli fall into Snyder \& Hansen's $\boldsymbol{F}$. oxysporum and the instability in vitro of such heterocaryons poses the problem of defining their taxonomic limits. Which of the many morphological variants capable of causing the disease is to be considered as the basic type for identification by making use of the traditional criteria for taxonomic division of the fusaria? Nuclei genetically pure for pionnotal and for non-pionnotal characteristics, for flat, white or for high, aerial, purple appearance can co-exist as heterocaryons. Such intermediates between taxa, that arise by anastomosis of germ tubes and subsequent migration of nuclei would, on cultivation from single spores, present the potential morphological range of the isolate to the observer. The selective nature of the medium will determine this range and the relative proportions of the taxa.

Jinks (1952) has analysed heterocaryosis in Penicillium cyclopium and concluded that the variation in the ratios of the different nuclei in the heterocaryon is adaptive in its significance. Although, as in the case of Fusarium oxysporum, the results of Jinks indicate that the relative numbers of the nuclear types are changed in relation to the medium, the possibility of ephemeral sectoring, which may or may not give rise to non-sporing sections of the colony, merits consideration. It is not, therefore, possible to be quite certain whether or not we are dealing with selection of nuclei or of short homocaryotic sporulating side-branches in an analysis of heterocaryons by 
the single-spore method. The selection of nuclei would be directly related to the ratio of the different types of sporulating side-branches when these are initially formed. In these respects, both Penicillium and Fusarium have their limitations in any interpretation of investigations of this kind.

It has become increasingly evident that comparisons of Fusarium isolates for purposes of identification must be made only on standard media and under identical cultural conditions. Gordon (1952) discussed the difficulties involved in the successful identification of Fusarium spp. and concluded that a knowledge of the wild-types from several different soil localities is required before a workable system of classification can be evolved. An investigation of the genetic constitutions of the wild-types in each section of Fusarium would provide a basis for such a classificatory system. $F$. oxysporum may exist in the soil as a heterocaryon or as a potential heterocaryon in the form of local concentrations of spores of different genotypes. As Baker (1944) pointed out, in relation to Penicillium notatum, the possession of uninucleate conidia does not preclude the possibility of the occurrence of heterocaryosis. As in the case of the evidence presented above, anastomosis of germ tubes from conidia reconstitutes the heterocaryon. The presence of a root or other suitable part of a host-plant may provide a selective environment for any or all of the nuclear types present. The occurrence of non-pathogenic 'mutants' from the wild-type isolates has long been known to occur. It is suggested that at least some such cases may be explained as arising by segregation in vitro of these 'extra' nuclei incidentally occurring in the hyphae invading' the host-plant. The proportions of pathogenic and non-pathogenic nuclei in wild-type isolates require investigation, and invasion of host-plant tissue might be studied from the standpoint of selective pressure on the nuclear types in the fusaria.

The author wishes to express his thanks to the Agricultural Research Council for the receipt of a Research Studentship, during part of the tenure of which this work was carried out, to Dr N. F. Robertson for many helpful suggestions, and to Mr F. T. N. Elborn for taking the photographs.

\section{REFERENCES}

ApPel, O. \& Wollenweber, H. W. (1910). Grundlagen einer Monographie der Gattung Fusarium (Link). Arb. biol. Abt. (Anst.-Reichsanst.), Berl. 8, 1-207.

Baker, G. E. (1944). Heterocaryosis in Penicillium notatum. Bull. Torrey bot. Cl. 71, 367.

Beadle, G. W. \& Coonradt, V. L. (1944). Heterocaryosis in Neurospora crassa. Genetics, 29, 291.

Brown, W. (1925). Studies in the genus Fusarium. II. An analysis of the factors which determine the growth-forms of certain strains. Ann. Bot., Lond. 39, 373.

Brown, W. (1926). Studies in the genus Fusarium. IV. On the occurrence of saltations. Ann. Bot., Lond. 40, 223.

Brown, W. (1928). Studies in the genus Fusarium. VI. General description of strains, together with a discussion of the principles at present adopted in the classification of Fusarium. Ann. Bot., Lond. 42, 285.

Brown, W. \& Horne, A. S. (1924). Studies in the genus Fusarium. I. General account. Ann. Bot., Lond. 38, 379. 
Brown, W. \& Honne, A. S. (1926). Studies in the genus Fusarium. III. An analysis of factors which determine certain microscopic features of Fusarium strains. Ann. Bot., Lond. 40, 203.

Buxton, E. W. \& Robertson, N. F. (1953). The Fusarium Yellows disease of Gladiolus. Plant Pathology, $2,61$.

Gondon, W. L. (1952). The occurrence of Fusarium species in cereal seed. Canad. J. Bot. 30, 209.

Hansen, H.N. (1938). The dual phenomenon in Imperfect Fungi. Mycologia, 30, 442.

Heubschman, C. (1952). A method for varying the average number of nuclei in the conidia of Neurospora crassa. Mycologia, 44, 599.

Jinks, J. L. (1952). Heterocaryosis-a system of adaptation in wild fungi. Proc. roy. Soc. B, 140, 83.

Massey, L. M. (1926). Fusarium rot of Gladiolus corms. Phytopathology, 16, 509.

MaCulloch, L. (1944). Fusarium Yellows of Gladiolus. Phytopathology, 34, 263.

Mrlefer, J. J. (1946). Cultural and taxonomic studies on certain fusaria. Canad. J. Res. C, 24, 188.

Ponteconvo, G. (1946). Genetic systems based on heterocaryosis. Cold Spr. Harb. Symp. quant. Biol. 11, 193.

Snyder, W. C. \& Hansen, H. N. (1940). The species concept in Fusarium. Amer. J. Bot. 27, 64.

SNYder, W. C. \& Hansen, H. N. (1945). The species concept in Fusarium with reference to Discolor and other sections. Amer. J. Bot. 32, 657.

Subramanian, C. V. (1951). Is there a 'wild-type' in the genus Fusarium? Proc. nat. Inst. Sci. India, 17, 403.

Wollenweber, H. W. \& Reinking, O. A. (1935). Die Fusarien. Berlin: Paul Parey.

\section{EXPLANATION OF PLATE}

Fig. 1. Spores of $F$. oxysporum f. gladioli variants 90 and $81 \mathrm{~A}$ showing nuclei (one per cell) stained with $2 \%$ aqueous Azure 'A'. $\times 1500$.

Fig. 2. Germinating conidia showing nuclear distribution and anastomoses between germ tubes. $\times 1500$.

Fig. 3. Anastomoses between hyphae of different homotypes-90 and $81 \mathrm{~A} . \times 1500$. 
Journal of General Microbiology, Vol. 10, No. 1
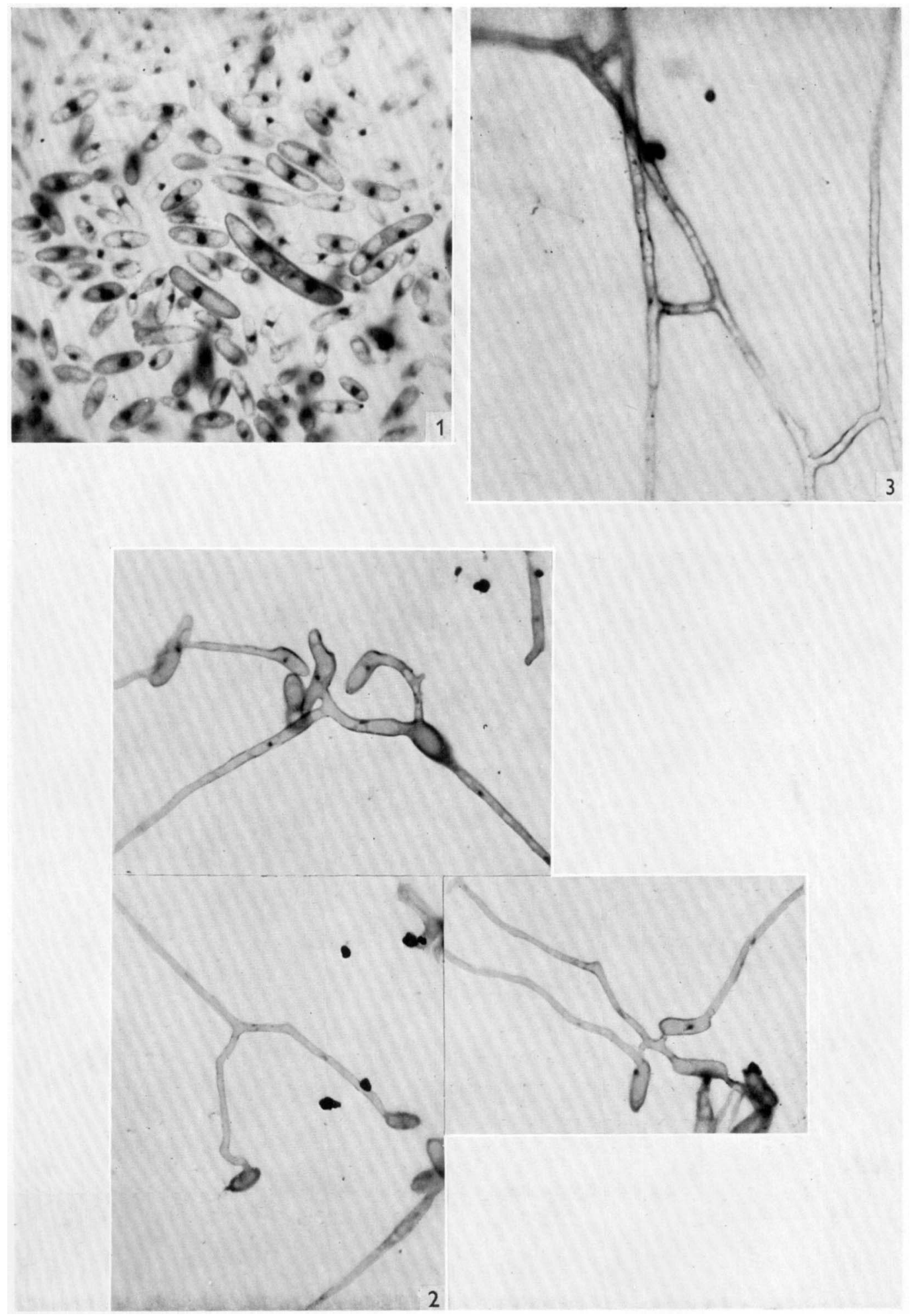

E. W. Buxton-Variability in Fusarium oxysportim. Piate 1 